\title{
Post-Traumatic Suprachoroidal Hemorrhage from Blunt Ocular Trauma
}

Parada Vásquez RH*, Medina Lopez J P, Cantu de la Garza A and del Valle Penella A

Department of Anterior Segment, VisionInstitute,

Hospital la Carlota, Montemorelos, Nuevo Leon, Mexico

*Corresponding author: Parada Vásquez RH,

Department of anterior segment, VisionInstitute,

Hospital la Carlota, Montemorelos, Nuevo Leon, Mexico

Received: J anuary 23, 2017; Accepted: February 17, 2017; Published: February 20, 2017

\section{Introduction}

Ocular trauma is a major cause of visual deterioration, resulting in as many as $40 \%$ of cases of monocular blindness worldwide [1]. Blunt trauma of the ocular globe is caused by an anterior-posterior compression, which results in a simultaneous expansion of the equatorial plane associated with a short-lived but severe increase in intraocular pressure (IOP) [2]. Although the impact is primarily absorbed by the crystalline-iris diaphragm and the vitreous base, the lesion may be produced at a distant location, such as the posterior pole [2]. Scleral ruptures caused by blunt trauma may be classified as: direct, those produced in the same place as the trauma, and indirect, which are produced at a distance from the trauma. The ruptures also affect the surrounding choroidal tissue, which is typically associated with significant hemorrhaging, both intraocular and subconjunctival [3]. Rao and collaborators suggest that a penetrating injury participates in the development of sympathetic ophthalmia, exposing the uveal-retinal antigens to the lymph of the conjunctiva, favoring the presentation of ocular antigens in the systemic immune system, thus creating a diffuse granulomatous uveitis that occurs within a few days up to several decades after a penetrating ocular trauma [4].

\section{Clinical Case}

Male patient, age 46 years with no known history of medical problems. States that 24 hours prior to his arrival in the emergency room, he suffered a fall from his own height, causing blunt trauma in the left ocular globe. He presented visual acuity, uncorrected distance vision: right eye (OD): 20/20 and left eye (OS): no light perception (NLP). Intraocular pressure: OD $14 \mathrm{mmHg}$ and OS: hypotonic upon palpation. Upon physical examination: Right eye without alterations. In the left eye (Figure 1), edema +++ is observed in the bulbar conjunctiva, presenting a lesion at the level of the superior nasal sclera measuring $3 \times 3 \mathrm{~mm}$ in diameter, displaying $360^{\circ}$ limbal ischemia (Figure 2) with extrusion of the transscleral uvea; cornea with superior sectorial edema and Descemet's membrane folds, anterior chamber formed with grade III hyphema, which does not permit evaluation of the other structures of the anterior segment and posterior. B-mode ultrasound is requested (Figures $3 \mathrm{a}$ and $3 \mathrm{~b}$ ), revealing temporal suprachoroidal hemorrhage, air in the vitreous chamber and detachment of the retina in the left eye.

The skull X-ray does not reveal extraocular alterations in the left orbit. Computed axialtomography (CAT) displays an image of loss of continuity in the left orbital floor, with extrusion of orbital material to the maxillary sinus. For this reason, conservative management is prescribed with antibiotics and non-steroidal analgesics. After two weeks, he is evaluated by oculoplastic services, who recommend

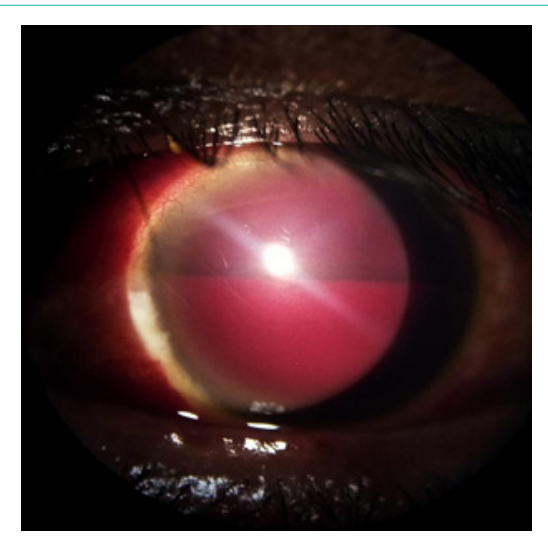

Figure 1: Hyphema occupying $50 \%$ of the anterior chamber volume, presence of supracoroid hemorrhage that prevents visualization of anterior segment structures.
Austin J Clin Ophthalmol - Volume 4 Issue 1 - 2017

ISSN : 2381-9162 | www.austinpublishing group.com

Parada Vásquez et al. @ All rights are reserved
Citation: Parada Vásquez RH, Medina Lopez JP, Cantu de la Garza A and del Valle Penella A. Post-Traumatic Suprachoroidal Hemorrhage from Blunt Ocular Trauma. Austin J Clin Ophthalmol. 2017; 4(1): 1075. 


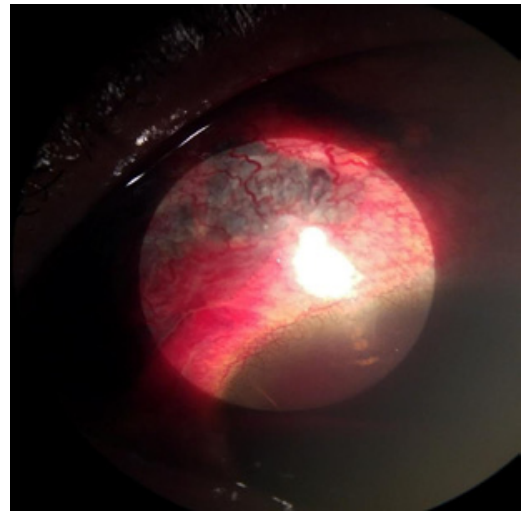

Figure 2: Uveal effusion, in the traumatized area of the upper nasal region.

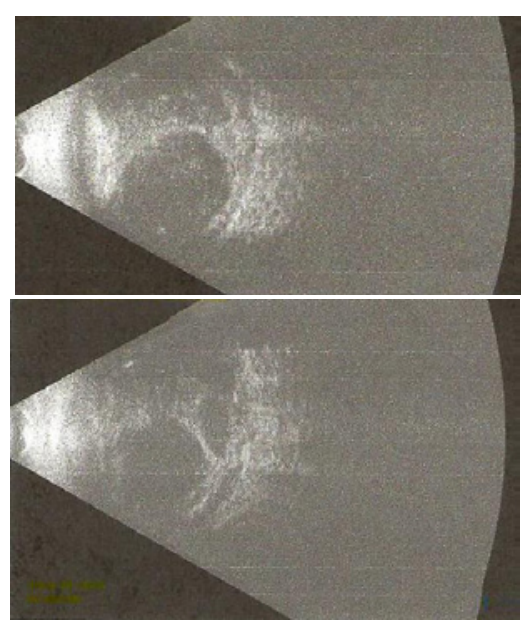

Figure $\mathbf{3 a}$ and $\mathbf{3 b}$ : B-mode ultrasound reveals temporal suprachoroida hemorrhage, air in the vitreous chamber and detachment of the retina in the left eye.

evisceration due to the risk of phthisis bulbi, as well as to decrease the risk of sympathetic ophthalmia. Two months after evisceration of the left eye, the patient is in stable condition.

\section{Discussion}

The present case investigates a patient who has received blunt trauma to the superior nasal region of the left eye. It is important to mention that in the case of trauma, the anterior segment is injured in isolation in more than half of cases, with injuries that affect only the posterior pole being rare. This case is a clear example of the dynamic forces of acceleration and deceleration at the intraocular level [5].

Previous studies in Mexico have shown that the most frequent retinal lesions causing visual deficiency in trauma are: commotio retinae, vitreous hemorrhage, retinal detachment and choroidal detachment. In the present case, these deficits are present, which have led to no light perception in the patient [6].

It is worth emphasizing that in the study by Hongsheng $\mathrm{Bi}$ performed at Shierming Eye Hospital, the mean age of ocular trauma was 37.2 years, primarily in men ( $85.3 \%$ of cases), as reflected in our case.

On the other hand, when damage to the choroid is found, there is no way to perform a suture, such that only the sclera may be sutured while keeping the choroidal rupture alignment; of course, this will be associated with a poor visual prognosis [7].

Other studies mention that the initial presentation of NLP after ocular trauma is presented in $30.7 \%$ of cases, making treatment very limited, as in our case [7].

The blood in the anterior chamber has been described in several reports as a result of iridodialysis or trauma to the vasculature of the iris $[8-9]$

Chandler and Maumenee, examined 50 hypotonic eyes from diverse surgical procedures, traumas and intraocular inflammation, finding detachment of the ciliary body in each patient [10].

\section{Conclusion}

As a conclusion, the visual prognosis would practically be eliminated in a patient who has suffered ocular trauma and is left with no light perception, extensive choroidal hemorrhage and retinal detachment; for this reason, it is important to perform image studies which are complementary in identifying severity in the clinical setting, in order to thus be able to prevent complications of endophthalmitis and sympathetic ophthalmia.

\section{References}

1. Wong TY, Klein BE, Klein R. The prevalence and 5-year incidence of ocular trauma. The beaver dam eye study. Ophthalmology 2000; 107: 2196-2202.

2. Kanski JJ, Bowling B. Kanski oftalmología clínica. 7. aed España: Elsevier; 2012. p. 878

3. Sánchez Ferreiro AV, Barreiro González JR. Rotura escleral traumática atípica: a propósito de un caso. Arch Soc Esp Oftalmol. 2012; 87: 253-255.

4. Del Campo-Briceño JM, Lizana-Henríquez C, Voorduin-Ramos S, PedrozaSeres M. Oftalmía simpática: serie de casos en un centro de referencia oftalmológico de la Ciudad de México. Rev Mex Oftalmol. 2009; 83: 143-150.

5. Fajardo Sánchez J, Chau Ramos CE, Mazagatos Useda PJ, Aparicio Hernandez-Lastras MJ. Efecto del traumatismo por aceleración/ desaceleración en estrías angioides: hipótesis patogénica. Arch Soc Esp Oftalmol. 2016; 91: 446-449.

6. Lima Gómez V, Albarrán Suárez E. Manejo inicial de las lesiones retinianas traumáticas en el Servicio de Urgencias. Rev Hosp Jua Mex. 2006; 73: 165169.

7. Hongsheng Bi, Yan Cui, Yang Li, Xingrong Wang, Jianhua Zhang. Clinical Characteristics and Surgical Problems of Ruptured Globe Injury. Curr Ther Res Clin Exp. 2013; 74: 16-21.

8. Dotan S, Oliver M. Shallow anterior chamber and uveal effusion after non perforating trauma to the eye. Am J Ophthalmol. 1982; 94: 782-784.

9. Srilakshmi Maguluri, Celyne L Bueno, Ira B Fuller, Ralph C Eagle, Derrick W Spell. Delayed Suprachoroidal Hemorrhage and Factor VIII Deficiency. Am J Ophthalmol. 2005; 139: 195-197.

10. Chandler PA, Maumenee, AE. A major cause of hypotony. Am J Ophthalmol. 1961; 52: 609-618. 